\title{
Discrepancy Between cTNM and pTNM in Patients with Oral Squamous Cell Carcinoma
}

\author{
Ramish Tariq, ${ }^{1}$, , Sana Mehmood Qureshi ${ }^{2}$, Muhammad Usman Khalid ${ }^{1}$, Omer Sefvan Janjua ${ }^{1}$, \\ Khurram Jah Zafar ${ }^{1}$, Malik Muhammad Usama ${ }^{1}$ \\ ${ }^{1}$ Oral and Maxillofacial Surgery, Allied Hospital, Faisalabad, Pakistan \\ ${ }^{2}$ Department of Oral Pathology, Allied Hospital, Faisalabad, Pakistan
}

\section{Email address:}

ramisht@ymail.com (R. Tariq), sana.mehmood@outlook.com (S. M. Qureshi),drusmankhalid82@hotmail.com (M. U. Khalid), osj1982@hotmail.com (O. S. Janjua), drkhurram1982@hotmail.com (K. J. Zafar), usamaomfs@gmail.com (M. M. Usama)

${ }^{*}$ Corresponding author

\section{To cite this article:}

Ramish Tariq, Sana Mehmood Qureshi, Muhammad Usman Khalid, Omer Sefvan Janjua, Khurram Jah Zafar, Malik Muhammad Usama. Discrepancy Between cTNM and pTNM in Patients with Oral Squamous Cell Carcinoma. International Journal of Clinical Oral and Maxillofacial Surgery. Vol. 7, No. 1, 2021, pp. 1-5. doi: 10.11648/j.ijcoms.20210701.11

Received: December 13, 2020; Accepted: January 11, 2021; Published: January 22, 2021

\begin{abstract}
Objective: To analyze discrepancy between cTNM and pTNM in patients with squamous cell carcinoma of oral cavity. Study design: Cross-sectional study. Setting \& Duration: Cases of OSCC treated in Oral and Maxillofacial Surgery Department, Allied Hospital Faisalabad from December 2017 to November 2020 were included in the study. Methodology: Total 80 patients with biopsy proven OSCC were enrolled in the study. cTNM staging was based on clinical examination and CT/MRI. Primary tumor excision along with neck dissection was done in all patients. Postoperatively pTNM staging was done and compared to cTNM. The clinical, radiological and histopathological lymph node status of patients were compared. Results: Among 80 patients, male to female ratio was 1.6:1. The mean of age was 50.2 \pm 10.2 years. The most common site in our center was the lateral border of the tongue. The total coincidence rate between clinical T-stage and pathological T-stage was $57.5 \%$. On comparison between the clinical and pathological N-stage the total coincidence rate was $40 \%$. The total coincidence rate between cTNM and pTNM was 35\% and the p-value was insignificant ( $p>0.05)$. The sensitivity of CT/MRI for N-stage was $53.3 \%$ and specificity was $60 \%$ and positive predictive value (PPV) was $53.3 \%$ and negative predictive value (NPV) was $60 \%$. Conclusion: Disparity between cTNM and pTNM of OSCC exits that could affect the treatment planning and prognosis.
\end{abstract}

Keywords: Oral cancer, Squamous Cell Carcinoma, TNM Staging

\section{Introduction}

Oral squamous cell carcinoma (OSCC) is the $8^{\text {th }}$ most common cancer in the world [1]. It accounts for $2-4 \%$ of all the cancers in the world and $10 \%$ of all cancers in Pakistan [2]. Each year 650,000 new cases and 350,000 deaths are reported globally, due to oral cancer [3]. Male to female ratio is $2: 1$ [4]. Mortality and morbidity in males is $6.6 / 100,000$ and $3.1 / 100,000$ and in females is 2.9/100,000 and $1.4 / 100,000$ respectively. The reported 5 -year survival is 40 $50 \%$ [2].

The etiology and predisposing factors of carcinoma of oral cavity includes smoking, alcohol, and areca nuts, as well as malnutrition, immunocompromised health status, infection from human papillomavirus (HPV), syphilis, oral thrush, poor oral hygiene, radiations, chronic irritation, occupational hazards and genetics $[5,6]$.

OSCC most commonly occurs at buccal mucosa, followed by tongue, mandibular alveolus, lip, floor of the mouth, hard palate and maxillary alveolus [7, 8]. OSCC may present clinically as lesion that is ulcerative, infiltrative, papillary, verrucous or combination of these [7].

Accurate TNM (tumor-lymph node-metastasis) staging is required for deciding the treatment options and the prognosis of the OSCC [9]. Inaccurate staging can result in positive tumor margins or excessive excision of the primary tumor as well as unnecessary lymph node dissection leading to surgical morbidity [10]. The 5 year survival rate is decreased in patients with cervical lymph node metastasis. Metastasis to 
the lymph nodes depends upon the site and size of the primary tumor, grade of tumor, involvement of perineural and perivascular tissues [11]. Clinically negative neck (occult metastasis) can be assessed by ultrasound guided fine needle aspiration, computed tomography (CT), magnetic resonance imaging (MRI), and positron emission tomography (PET) [12]. Occult metastasis is present in $12-50 \%$ of OSCC cases. Lymph node metastasis can best be diagnosed by histopathology [13].

Management of OSCC is multimodal comprising of primary tumor excision with or without neck dissection, radiotherapy, chemotherapy and combination of these modalities [13]. The management of clinical N0 is controversial. The conservative management is opposed to elective neck dissection in clinical N0. Conservative management in case of clinical N0 and occult neck metastasis can lead to spread of the disease and neck dissection in case of absent lymph node metastasis is considered an over treatment [12]. Hence the objective was to correlate clinical, radiographic and postoperative TNM to find out the accuracy of cTNM and the discrepancy between cTNM and pTNM.

\section{Material and Method}

A cross sectional study was conducted in Oral Maxillofacial Surgery, Allied Hospital Faisalabad after taking approval from hospital ethical review committee. Patients who met the inclusion criteria were included. In this study, 80 patients were enrolled from December 2017 to November 2020.

\subsection{Inclusion Criteria}

Patients with oral squamous cell carcinoma that was biopsy proven, and underwent surgery of the primary tumor and neck dissection irrespective of the lymph node metastasis status were included.

\subsection{Exclusion Criteria}

Patients were not included in the study, who had undergone chemotherapy, radiotherapy or combination of these therapies.

\subsection{Methodology}

Staging was done according to AJCC/UICC $8^{\text {th }}$ edition [14]. Patient's history, clinical examination, the size and site of primary tumor, metastasis to lymph node and TNM staging were done. For evaluation of metastasis to lymph node, all the patients were advised post contrast CT scan or MRI. The diagnostic criteria for N0 was lymph node size less than $1 \mathrm{~cm}$, without central necrosis, calcification, cluster distribution or no lymphadenopathy on imaging [15]. All the patients treated by primary tumor excision and neck dissection following NCCN guidelines [16]. Surgical specimens were examined macroscopically and microscopically and pathological TNM was evaluated and results were collected.

Clinical tumor and nodal stage was compared to pathological tumor and nodal stage and results were calculated to find the discrepancies. Clinical TNM stage was compared to pathological TNM stage to evaluate the stage migration (up-stage, down-stage and no change).

Data was analyzed using SPSS-20. For quantitative variables like age, mean and standard deviation were calculated. For qualitative variables like, gender, site of tumor, clinical T-stage, clinical N-stage, pathological T-stage, pathological N-stage, clinical TNM and pathological TNM stage, frequencies and percentages were calculated. Chisquare test was applied and $\mathrm{p}$ value $\leq 0.05$ was considered statistically significant.

\section{Results}

Among 80 patients, 50 were male and 30 were female. Male to female ratio was $1.6: 1$. The age range was $27-70$ years with mean of age $50.2 \pm 10.2$ years.

Lateral border of tongue was involved in 34 (42.5\%) patients, buccal mucosa in $22(27.5 \%)$, mandibular alveolus in $18(22.5 \%)$, commissure of mouth in $4(5 \%)$ and lower lip in $2(2.5 \%)$ patient.

The distribution of cTNM stages were T1 in $24(30 \%)$ patients, T2 in $30(37.5 \%), \mathrm{T} 3$ in $8(10 \%), \mathrm{T} 4 \mathrm{a}$ in $16(20 \%)$ and T4b in $2(2.5 \%)$ patient. N0 was present in $50(62.5 \%)$ patients, $\mathrm{N} 1$ in $18(22.5 \%), \mathrm{N} 2 \mathrm{~b}$ in $4(5 \%)$ and $\mathrm{N} 2 \mathrm{c}$ in $8(10 \%)$ patients.

The distribution of pTNM were T1 in $10(12.5 \%)$ of patients, T2 in $35(43.8 \%), \mathrm{T} 3$ in $21(26.2 \%)$, T4a in 14 $(17.5 \%)$ of patients. N0 was present in $44(55 \%)$ patients, N1 in $16(20 \%), \mathrm{N} 2 \mathrm{~b}$ in $14(17.5 \%), \mathrm{N} 3 \mathrm{~b}$ in $6(7.5 \%)$ patient.

On comparison between clinical tumor-stage (cT) and pathological tumor-stage (pT), the total coincidence rate was $57.5 \%$ and between $\mathrm{T} 1, \mathrm{~T} 2, \mathrm{~T} 3$, and T4a were $25 \%, 66.6 \%$, $100 \%$, and $75 \%$ respectively (Table 1 ).

On comparison between clinical nodal-stage $(\mathrm{cN})$ and pathological nodal-stage $(\mathrm{pN})$, the total coincidence rate was 40\% (Table 2).

Approximately, 40\% (20/50) of cN0 cases were upstaged to $\mathrm{pN} 1, \mathrm{pN} 2$ or $\mathrm{pN} 3,44 \%(8 / 18)$ cases of $\mathrm{cN} 1$ were downstaged to $\mathrm{pN} 0$ and $44 \%(8 / 18)$ were upstaged to $\mathrm{pN} 2$ or $\mathrm{pN} 3,100 \%(12 / 12)$ cases of $\mathrm{cN} 2$ were downstaged to $\mathrm{pN} 0$ or pN1. In summary 20 cases were down-staged, and 28 were up-staged postoperatively and 32 patients had same clinical and pathological $\mathrm{N}$ stage. Among the 30 cases of clinically positive lymph nodes 14 (46\%) patients were free of lymph node metastasis.

Distant metastasis was assessed by CT chest and USG abdomen, which proved that preoperative $M$ stage was consistent with postoperative $\mathrm{M}$ stage.

On comparison between cTNM and pTNM, the total coincidence rate was $35 \%$ (Table 3 ). Out of 18 patients in clinical stage I $77.7 \%(14 / 18)$ were upstaged to pathological stage II, III, or IV, $54.5 \%$ (12/22) with clinical stage II were upstaged to pathological stage III or IVa, 40\% (4/10) with 
clinical stage III were downstaged to pathological stage I or stage II and $20 \%(2 / 10)$ were upstaged to stage IVa or IVb, $57 \%(16 / 28)$ with clinical stage IVa were downstaged and $32 \%$ $(2 / 28)$ were upstaged to IVb postoperatively. This stage shift was mainly due to stage shift in clinical $\mathrm{N}$ stage. The p-value was not significant $(\mathrm{p}=0.06)$

The sensitivity of CT/MRI for N-stage was $53.3 \%$ and specificity was $60 \%$ with positive predictive value (PPV) of $53.3 \%$ and negative predictive value (NPV) of $60 \%$.

Table 1. Comparison of clinical and pathological T stage for oral cancer.

\begin{tabular}{|c|c|c|c|c|c|c|c|c|}
\hline T-stage & pT1 & pT2 & pT3 & pT4a & pT4b & Total & Coincidence ratio & Coincidence rate $\%$ \\
\hline cT1 & 6 & 13 & 5 & 0 & 0 & 24 & $6 / 24$ & $25 \%$ \\
\hline $\mathrm{cT} 2$ & 2 & 20 & 6 & 2 & 0 & 30 & $20 / 30$ & $66.6 \%$ \\
\hline cT3 & 0 & 0 & 8 & 0 & 0 & 8 & $8 / 8$ & $100 \%$ \\
\hline cT4a & 0 & 2 & 2 & 12 & 0 & 16 & $12 / 16$ & $75 \%$ \\
\hline cT4b & 2 & 0 & 0 & 0 & 0 & 2 & $0 / 2$ & $0 \%$ \\
\hline Total & 10 & 35 & 21 & 14 & 0 & 80 & $46 / 80$ & $57.5 \%$ \\
\hline
\end{tabular}

Table 2. Comparison of clinical and pathological $N$-stage for oral cancer.

\begin{tabular}{|c|c|c|c|c|c|c|c|}
\hline N-stage & pNo & pN1 & pN2 & pN3 & Total & Coincidence ratio & Coincidence rate $\%$ \\
\hline $\mathrm{cNO}$ & 30 & 8 & 8 & 4 & 50 & $30 / 50$ & $60 \%$ \\
\hline $\mathrm{cN} 1$ & 8 & 2 & 6 & 2 & 18 & $2 / 18$ & $11 \%$ \\
\hline $\mathrm{cN} 2$ & 6 & 6 & 0 & 0 & 12 & $0 / 12$ & $0 \%$ \\
\hline $\mathrm{cN} 3$ & 0 & 0 & 0 & 0 & 0 & 0 & $0 \%$ \\
\hline Total & 44 & 16 & 14 & 6 & 80 & $32 / 80$ & $40 \%$ \\
\hline
\end{tabular}

Table 3. Comparison of clinical and pathological TNM stage for oral cancer.

\begin{tabular}{|c|c|c|c|c|c|c|c|c|}
\hline Stage & $\begin{array}{l}\text { Pathological } \\
\text { I }\end{array}$ & $\begin{array}{l}\text { Pathological } \\
\text { II }\end{array}$ & $\begin{array}{l}\text { Pathological } \\
\text { III }\end{array}$ & $\begin{array}{l}\text { Pathological } \\
\text { Iva }\end{array}$ & $\begin{array}{l}\text { Pathological } \\
\text { IVb }\end{array}$ & Total & $\begin{array}{l}\text { Coincidence } \\
\text { ratio }\end{array}$ & Coincidence rate \\
\hline Clinical I & 4 & 4 & 4 & 4 & 2 & 18 & $4 / 18$ & $22.2 \%$ \\
\hline Clinical II & 0 & 10 & 6 & 6 & 0 & 22 & $10 / 22$ & $45.4 \%$ \\
\hline Clinical III & 2 & 2 & 4 & 0 & 2 & 10 & $4 / 10$ & $40 \%$ \\
\hline Clinical IVa & 2 & 4 & 10 & 10 & 2 & 28 & $10 / 28$ & $35.7 \%$ \\
\hline Clinical IVb & 0 & 0 & 0 & 2 & 0 & 2 & $0 / 2$ & $0 \%$ \\
\hline Total & 8 & 20 & 24 & 22 & 6 & 80 & $28 / 80$ & $35 \%$ \\
\hline
\end{tabular}

\section{Discussion}

Accurate TNM staging is important for the treatment of oral carcinoma as it helps in the proper treatment planning and predicting the prognosis [17]. Nodal involvement is one of the most important prognostic factor in oral cancer. The survival rate is reduced by $50 \%$ in patients with single ipsilateral metastasis or contralateral lymph node metastasis and further decreased by $50 \%$ in bilateral lymph node metastatic regardless of the site of primary tumor [18].

Out of 80 patients in our study, 50 were male and 30 were female with ratio of 1.6:1 showing a male predominance. The male predominance is because of the greater frequency of smoking in men than women in Asia. In comparison to our study, Mehta et al. and Essig et al. in their study had shown male predominance with $3: 1[11,13]$.

Among the 80 patients in our study, mean age was 50 years. Nithya et al. reported similar results in their study as oral squamous cell carcinoma is more frequent in middle age from third to fifth decade [19]. Mehta et al. also had also shown in their study that the mean of age in OSCC patients was 45.5 years [11].

In our study, lateral border of the tongue (42.5\%) was the most common site of squamous cell carcinoma and the second most frequent site was buccal mucosa (27.5\%). Gupta et al. also found that tongue was involved in $33 \%$ and buccal mucosa in $29 \%$ of cases [20]. In contrast, Mehta et al. found that buccal mucosa was affected in $33 \%$ and tongue in $24 \%$ of patients [11]. Tandon et al. in their study also found that buccal mucosa was involved in $45.9 \%$ of cases [21].

At our institute patients commonly presented in advanced stage of IVa (35\%), stage III (12.5\%), stageII (27.5\%), stage I $(22.5 \%)$ and. In comparison to that Mehta et al. in their study found that most of the patients had stage III and IV [11].

In our study, the total coincidence rate of clinical T-stage (cT) and pathological T-stage (pT) was $57.5 \%$ and clinical Nstage $(\mathrm{cN})$ and pathological $\mathrm{N}$-stage $(\mathrm{pN})$ was $40 \%$. The coincidence rate of cTNM and pTNM was $35 \%$. Tianrum et al. in their study had shown the coincidence rate of clinical and pathological T-stage was $78.7 \%, \mathrm{~N}$-stage was $58.8 \%$ and TNM stage was $58.5 \%$. $66.9 \%$ of the cases in their study had clinically enlarged lymph node that were non-metastatic postoperatively whereas $18.7 \%$ of cases with cN0 were proved to have metastasis postoperatively [9]. In our study, $46 \%$ of cases with clinically positive lymph node were negative for metastasis whereas $40 \%$ of cN0 were found to have metastatic deposits postoperatively.

The most likely causes of staging discrepancy between clinical TNM and pathological TNM were delay in clinical diagnosis and pathological analysis leading to upstaging, lack of accurate clinical staging tools that includes physical examination of the nodes that may be subjectively different 
based on surgeon's experience. The lower limit of lymph node palpation in superficial areas is $0.5 \mathrm{~cm}$ and $1 \mathrm{~cm}$ in deeper areas [22]. The most common imaging modality for the diagnosis of metastasis to lymph node is CT and MRI. It is hard to confirm that it is benign or malignant [9]. In our study $46 \%$ of patients with $\mathrm{cN} 1-\mathrm{N} 3$ were pN0. Lymph nodes with $<1 \mathrm{~cm}$ may be metastatic but may be hard to find on clinical examination and CT. Reported incidence of metastasis to cervical lymph node in cN0 ranged from $18-30 \%$ [15] and in our study was $40 \%$.

The sensitivity of CT/MRI in our study for lymph node metastasis was $53.3 \%$ and specificity was $60 \%$. De Bondt et al. in their study had shown that the sensitivity of CT ranged from $55-95 \%$ and specificity from $39-96 \%$ whereas MRI had sensitivity and specificity of $64-92 \%$ and $40-81 \%$ respectively [23]. Bipat et al reported sensitivity of MRI was $60 \%$ and $\mathrm{CT}$ was $43 \%$ [24].

The range of delay was 7-28 days and mean of delay was 14 days in clinical staging and pathological analysis that resulted in upstaging. MRI has high accuracy in detecting the lymph node metastasis but due to high cost of MRI and non-affordability of patients and to evaluate bone invasion CT was advised.

\section{Conclusion}

Stage shift was noted in our study that was mainly due to discrepancy between clinical N-stage and pathological Nstage. Metastasis to cervical lymph nodes can be determined on CT and MRI but histopathology is gold standard. Discrepancy does exist between clinical and pathological staging that could alter the treatment planning and affect survival of patients with OSCC. Hence more studies need to be done to find out the discrepancy between clinical TNM and pathological TNM staging and sensitivity and specificity of CT/MRI for lymph node metastasis evaluation.

\section{Recommendation}

Keeping in view the minimal morbidity and mortality of neck dissection in OSCC, neck dissection should be performed in all cases where there is any possibility of occult metastasis and minimal number of patients should be kept on conservative management.

\section{Conflict of Interest}

The authors declare that they have no competing interests.

\section{References}

[1] Carvalho KM, Sawant PR, Dhupar A, Spadigam A. A case of oral squamous cell carcinoma in a nontobacco habitue. Int $\mathrm{J}$ App Basic Med Res. 2017; 7: 278-80.

[2] Markopoulos AK. Current aspects on oral squamous cell carcinoma. Open Dent J. 2012; 6: 126-30.

[3] Saira, Khan MF, Khattak MR, Ahmed R, Malik S. Epidemiological and clinical correlates of oral squamous cell carcinoma in patients from north-west Pakistan. J Pak Med Assoc. 2019; 69: 1074-78.

[4] Salian V, Dinakar C, Shetty P, Ajila V. Etiological trends in oral squamous cell carcinoma: a retrospective institutional study. Cancer Transl Med. 2016; 2: 33-6.

[5] Nanvati MKR, Modi TG, Dobariya C. Oral cancer: etiology and risk factors: a review. J Can Res Ther. 2016; 12: 458-63.

[6] Akubulut N, Oztas B, Kursun S, Evergin S. Delayed diagnosis of oral squamous cell carcinoma: a case series. J Med Case Reports. 2011; 5; 1-5.

[7] Mathur PT, Dayal PK, Pai KM. Correlation of clinical patterns of oral squamous cell carcinoma with age, site, sex, and habits. J Indian Acad Oral Med Radiol. 2011; 23: 81-5.

[8] Smitha T, Mohan CV, Hemavathy S. Clinicopathological features of oral squamous cell carcinoma: a hospital-based retrospective study. J NTR Univ Health Sci. 2017; 6: 29-34.

[9] Liu T, Xie L, Xu H, Wang W, Zhuang S, Long Z, et al. Discrepancy between cTNM and postoperative pTNM stage of oral squamous cell carcinoma. J Med Discov. 2017; 2: 1-6.

[10] Choi N, Noh Y, Lee EK, Chung M, Baek CH, Baek KH, et al. Discrepancy between cTNM and pTNM staging of oral cavity cancers and its prognostic significance. J Surg Oncol. 2017; 115: $1-8$.

[11] Essig H, Warriach R, Zulfiqar G, Rana M, Eckardt AM, Gellrich NS, et al. Assessment of cervical lymph node metastasis for therapeutic decision-making in squamous cell carcinoma of buccal mucosa: a prospective clinical analysis. World J Surg Oncol. 2012; 10: 1-6.

[12] Van den Brekel MW, Van der Waal I, Meijer CJ, Freeman JL, Castelijns JA, Snow GB. The incidence of micrometastases in neck dissection specimens obtained from elective neck dissections. Laryngoscope. 1996; 106: 987-91.

[13] Mehta N, Sharma R, Madhok R, Agrawal T, Sharma V. A clinical, radiological, and histopathological correlation of neck nodes in patients undergoing neck dissection. Int $\mathrm{J}$ App Basic Med Res. 2018; 8: 9-13.

[14] Shah JP, Montero PH. New AJCC/UICC staging system for head and neck, and thyroid cancer. Rev Med Clin Condes. 2018; 29: 397-404.

[15] Guo ZM, Zeng ZY, Chen FJ, Peng HW, Wei MW, Zhang Q, et al. Management option for cervical metastases in tongue squamous cell carcinoma with clinically N0 neck. Chin J Otorhinolaryngol Head Neck Surg. 2005; 40: 91-4.

[16] Adelstein D, Gillison ML, Pfister DG, Adkins D, Brizel DM, Burtness B, et al. NCCN guidelines insights: head and neck cancers, version 2.2017. J Natl Compr Canc Netw. 2017; 15: $761-70$.

[17] Edge SB, Compton CC. The American joint committee on cancer: the $7^{\text {th }}$ edition of the AJCC cancer staging manual and the future of TNM. Ann Surg Oncol. 2010; 17: 1471-74.

[18] Richard PS, Peacock TE. The role of ultrasound in the detection of cervical lymph node metastasis in clinically N0 squamous cell carcinoma of the head and neck. Cancer imaging. 2017; 7: 167-78.

[19] Nithya C, Pandey M, Naik B, Ahmed IM. Patterns of cervical metastasis from carcinoma of the oral tongue. World J Surg Oncol. 2003; 1: 1-6. 
[20] Gupta K, Panda NK, Bakshi J, Das A. To evaluate disparity between clinical and pathological tumor-nod-metastasis staging in oral cavity squamous cell carcinoma patients and its impact on overall survival: an institutional study. South Asian J Cancer. 2015; 4: 183-5.

[21] Tandon A, Bordoloi B, Jaiswal R, Srivastava A, Singh R, Shafique U. Demographic and clinicopathological profile of oral squamous cell carcinoma patients of North India: a retrospective institutional study. SRM J Res Dent Sci. 2018; 9: 114-8.

[22] Greenberg JS, El Naggar AK, Mo V, Roberts D, Myers JN. Disparity in pathologic and clinical lymph node staging in oral tongue carcinoma. Implication for therapeutic decision making. Cancer. 2003; 98: 508-15.

[23] De Bondt RB, Nelemans PJ, Hofman PA, Casselman JW, Kremer B, Engelshoven JMA, et. al. Detection of lymph node metastases in head and neck cancer: A meta-analysis comparing US, USgFNAC, CT and MR imaging. Eur J Radiol. 2007; 64: 266-72.

[24] Punchai N, Dongarwar GR, Mahajan H, Daniel MJ, Chalapathi KW, Nayyar AS. Tumor size and its relation to cervical lymph node metastasis and its significance as a prognostic indicator for oral squamous cell carcinoma. Clin Cancer Investig J. 2017; 6: 153-66. 